\title{
Temperature and pressure dependence of density of a shale oil and derived thermodynamic properties
}

\author{
Zachariah S. Baird ${ }^{1}$, Petri Uusi-Kyyny ${ }^{1}$, Oliver Järvik², Vahur Oja ${ }^{2 *}$, Ville Alopaeus ${ }^{1}$
}

\begin{abstract}
The temperature and pressure dependence of density was measured experimentally from 293 to $473 \mathrm{~K}$ and 0.1 to $12 \mathrm{MPa}$ for a shale oil produced from Kukersite oil shale in Estonia. The shale oil sample was a fuel oil fraction of a whole oil produced in a commercial plant that uses solid heat carrier retorting technology. The fraction had a boiling range of approximately 460 to $780 \mathrm{~K}$ and contained significant quantities of polar phenolic compounds (hydroxyl group content of $5.3 \mathrm{wt} \%$ ). The effect of these compounds on the properties of the oil was investigated by removing most of the phenolic compounds via extraction to create the second sample (dephenolated sample with hydroxyl group content of $1.1 \mathrm{wt} \%)$. The dephenolation resulted in a shale oil with a composition being more similar to that of other shale oils from well explored deposits. Based on a review of the literature, this is the first experimental data on the pressure dependence of density for this shale oil, and shale oils generally. Thermal expansion coefficients, isothermal compressibilities and speeds of sound were calculated from the experimental data. Empirical relationships describing the temperature dependence of the heat capacities between 288 and $423 \mathrm{~K}$ at atmospheric pressure are also presented here.
\end{abstract}

Keywords: density, thermal expansion coefficient, isothermal compressibility, speed of sound, shale oil, Kukersite oil shale, heat capacity

\section{Introduction}

Information about thermodynamic properties is important for designing and modeling chemical processes. Because materials can be subject to a range of temperatures and pressures, it is important to know how the properties of a substance change with temperature and pressure. Data for thermodynamic properties, including density, heat capacity or the speed of sound, can provide this information, and this data can then be used for determining parameters for equations of state. ${ }^{1,2}$

Although data on the pressure dependence of density gives valuable information for developing processes to upgrade shale oil to motor fuels, to our knowledge no data exists in the public literature for the density of Kukersite shale oil, or shale oils generally, at high temperatures and pressures. ${ }^{3}$ For petroleum fuels densities and other properties can often be estimated by using equations of state and empirical correlations, but prediction methods based on conventional fuels may not perform accurately for shale oils because of their different composition. ${ }^{3-7}$ For this reason, prior experimental verification is necessary.

Oil shale is a source of energy and liquid fuel that attracts attention from time to time due to the large reserves available around the world. However, oil shale has never been a significant global source of energy due to the relatively high cost of obtaining energy from it and its large environmental footprint. ${ }^{8}$ Nevertheless, it has been estimated that $4.7 \cdot 10^{12}$ barrels of oil could be produced from the known reserves, ${ }^{9}$ and oil shale has been an important local resource in several countries. ${ }^{10}$ For example, shale oil has been produced

1 Department of Chemical and Metallurgical Engineering, Aalto University, P.O. Box 16100, Fl-00076 Espoo, Finland

2 Department of Energy Technology, Tallinn University of Technology, Ehitajate tee 5, 19086 Tallinn, Estonia

* Corresponding author: vahur.oja@ttu.ee, +3726202852 
in Estonia for about a century, ${ }^{11}$ and shale oil is produced on an industrial scale in other countries as well (e.g. Brazil and China). ${ }^{9}$

In contrast to conventional petroleum production, shale oil is produced from solid oil shale via pyrolysis (the industrial process is called retorting). ${ }^{10,12}$ The composition of shale oil can vary depending on the composition of the raw oil shale and the retorting method (i.e. pyrolysis method) used for producing the oil. ${ }^{13,14}$ Shale oils often contain large quantities of alkyl aromatic and heteroatomic compounds, making them different from conventional petroleum. ${ }^{10,15}$ Their composition also makes them an interesting option for developing and testing thermodynamic correlations for liquid fuels. For example, shale oil produced from Kukersite oil shale (Estonia) contains a large number of oxygenated compounds, the majority of which have an alkylphenolic nature. ${ }^{5,6,16}$ This high oxygen content gives Kukersite shale oil a composition that is somewhere between conventional petroleum and biofuels, and studying it can help bridge the gap between different fuels to create a unified thermodynamic model. Because the differences in composition affect the properties of the oil, it has been found that conventional prediction methods used for petroleum fuels can give erroneous predictions for Kukersite shale oil. ${ }^{17-19}$ This makes experimental data all the more important for these types of fuels. This article presents, to our knowledge, the first experimental data that examines the pressure dependence of density for Kukersite shale oil.

\section{Experimental}

\subsection{Sample preparation}

The shale oil sample was obtained from Eesti Energia's Narva Oil Plant (Auvere, Estonia). This plant uses solid heat carrier retorting technology (also known as the Galoter process), ${ }^{20-22}$ and uses Kukersite oil shale (from the Baltic oil shale basin in Estonia) as the raw material. The plant separates the crude shale oil into three wide fractions (gasoline, fuel oil and heavy oil fractions), and a sample of fuel oil was used for these measurements. Kukersite shale oil contains significant amounts of polar phenolic compounds, often amounting to about half of the whole shale oil. ${ }^{16}$ To investigate the effect these polar compounds have, extraction was used to remove the phenolic compounds from a portion of the shale fuel oil to create a second sample. By removing the phenolic compounds the composition of the fuel also becomes more similar to that of other shale oils that do not contain as much oxygen. ${ }^{15}$ The procedure involves extraction with $10 \% \mathrm{NaOH}$, washing with distilled water and drying the oil..$^{5,16,23}$ The hydrogen solubilities of these same samples were also measured as part of a separate set of experiments. ${ }^{23}$

\subsection{Sample characteristics}

Characteristic properties of the fuel oil and its dephenolated subfraction are given in Table 1. Due to the removal of phenolic compounds using $10 \% \mathrm{NaOH}$, the dephenolated oil sample had a somewhat lower specific gravity and refractive index, but a higher number average molecular weight than the initial oil. The specific gravity values correspond to API gravities of 7.2 and 14.2 for the fuel oil and dephenolated fuel oil, respectively.

Table 1. Properties of the shale oil samples used in this study and their expanded uncertainties at the 95\% level.

\begin{tabular}{l|cc}
\multicolumn{1}{c|}{ Characteristic } & Fuel oil & Dephenolated oil \\
\hline Specific gravity $\left(20^{\circ} \mathrm{C} / 4^{\circ} \mathrm{C}\right)$ & $1.0170 \pm 0.0003$ & $0.9682 \pm 0.0003$ \\
Refractive index at $293 \mathrm{~K}$ & $1.557 \pm 0.0021$ & $1.541 \pm 0.0021$ \\
Molecular weight $\left(\mathrm{g} \mathrm{mol}^{-1}\right)$ & $240 \pm 14$ & $250 \pm 14$
\end{tabular}




\begin{tabular}{l|cc} 
Hydrogen content $(w t \%)$ & $9.4 \pm 0.28$ & $10.7 \pm 0.28$ \\
Carbon content $(w t \%)$ & $80.9 \pm 1.3$ & $82.5 \pm 1.3$ \\
H/C ratio & $1.38 \pm 0.033$ & $1.55 \pm 0.033$ \\
Hydroxyl group content $(w t \%)$ & $5.3 \pm 0.72$ & $1.1 \pm 0.72$ \\
\hline
\end{tabular}

The infrared spectra of the samples, which gives information about the functional groups they contain, can be found at https://osf.io/dhkew/. Based on these spectra the hydroxyl group, hydrogen and carbon contents were calculated via support vector regression models developed in our laboratory ${ }^{24}$ and these values are also given in Table 1 . These values indicate that the dephenolated fuel oil had a higher atomic $\mathrm{H} / \mathrm{C}$ carbon ratio and a significantly lower hydroxyl group content than the initial fuel oil. In this study, only the carbon and hydrogen contents were determined. The remaining $9.8 \%$ and $6.8 \%$ for the fuel oil and dephenolated fuel oil, respectively, was mostly oxygen with some sulfur and nitrogen. ${ }^{15,16}$ The sulfur and nitrogen contents are known to be relatively small, less than $1.5 \% .^{15}$

The vaporization curves of the oil samples, which approximate the boiling point distributions of the samples, were evaluated using a thermogravimetric analyzer. ${ }^{25}$ These curves indicated that the boiling range of both samples was approximately 460 to $770 \mathrm{~K}$. For both samples the majority boils above $473 \mathrm{~K}$ at atmospheric pressure, which is the highest temperature at which densities were measured at elevated pressures. Therefore, the measured ranges do not extend down to where saturated liquid densities occur.

\subsection{Experimental methods}

\subsubsection{Density at atmospheric pressure}

Densities were measured at atmospheric pressure from 293 to $353 \mathrm{~K}$ using a DMA 5000M density meter (Anton Paar $\mathrm{GmbH}$, Graz, Austria). This was done because the high pressure density meter had difficulty reaching atmospheric pressure and required the sample to be degassed. The standard uncertainty of the measured data was $0.15 \mathrm{~kg} \mathrm{~m}^{-3}$ (expanded uncertainty of $0.3 \mathrm{~kg} \mathrm{~m}^{-3}$ at the $95 \%$ level). This is a relative expanded uncertainty of about $0.03 \%$. The manufacturer states the repeatability of the temperature data as being $0.001 \mathrm{~K}$.

\subsubsection{Density at high pressure}

Density measurements at high pressure were performed using a DMA HPM density measurement cell (Anton Paar $\mathrm{GmbH}$, Graz, Austria) in the range of 293 to $473 \mathrm{~K}$ and 0.15 to $12 \mathrm{MPa}$. The density meter was calibrated with nitrogen and pure water. Reference data for nitrogen and pure water were taken from reference equations of state, ${ }^{26,27}$ which are implemented in CoolProp's ${ }^{28}$ Excel add-in. The accuracy of CoolProp's implementation was checked by manually comparing the densities at multiple temperatures and pressures with the NIST thermophysical properties calculator, ${ }^{29}$ which also implements the same equations of state. All values checked were the same. Based on the calibration the standard uncertainty of the device was estimated to be $0.047 \mathrm{~kg} \mathrm{~m}^{-3}$ (expanded uncertainty of $0.091 \mathrm{~kg} \mathrm{~m}^{-3}$ at the $95 \%$ level). The pressure sensor used for measuring the density in the density measurement cell was calibrated against a Beamex MC2-PE calibrator with an EXT600 external pressure module, which had been calibrated by Beamex Oy Ab. Based on this calibration the standard uncertainty of the pressure data is $0.0031 \mathrm{MPa}$ (expanded uncertainty of $0.0063 \mathrm{MPa}$ at the $95 \%$ level). For the measured temperature the manufacturer only states that its accuracy is better than $0.1 \mathrm{~K}$.

The samples were degassed before being fed into the density meter. For the shale fuel oil the weight was measured before and after degassing, and $0.6 \mathrm{~g}$ was lost during degassing (or $1.1 \%$ of the sample by mass). The effect of this loss can be estimated by comparing 
the density values at $293 \mathrm{~K}$ measured at atmospheric pressure (without degassing) and in the DMA HPM. Using Equation 6, the density at $0.1 \mathrm{MPa}$ and $293.2 \mathrm{~K}$ was calculated to be $1018.0 \mathrm{~kg} \mathrm{~m}^{-3}$ (experimental data at $0.152 \mathrm{MPa}$ gives the same value). Thus, the difference due to degassing can be estimated to be an increase of $1 \mathrm{~kg} \mathrm{~m}^{-3}$.

The viscosity of a sample can also affect the density measurements made using the oscillating tube method, ${ }^{30}$ so a viscosity correction was applied to the measured data. Although the viscosity correction is small (no more than $0.07 \%$ of the density value), it was still taken into account to achieve a better accuracy. For the purposes of this study, the viscosity correction factor was defined as the relative deviation of the actual density from that measured by the density meter (see Equation 1).

$$
f=\frac{\left(\rho-\rho_{\text {non }}\right)}{\rho_{\text {non }}}
$$

In Equation $1 f$ is the viscosity correction factor, $\rho$ is the "true" density with the viscosity correction applied and $\rho_{\text {non }}$ is the non-corrected density given by the density meter.

The viscosity correction was calculated based on information from Stabinger ${ }^{30}$ and 232 experimental data points for other oil shale fractions that had been measured at atmospheric pressure with a density meter that included an automatic viscosity correction (DMA 5000M, Anton Paar GmbH, Graz, Austria). First, the viscosity correction factor was calculated for the experimental data points. This was then combined with experimental viscosity data for these other oil shale fractions to determine how the viscosity correction factor varied with sample viscosity. Based on this information it was found that when the viscosity is greater than $500 \mathrm{mPa} \cdot \mathrm{s}$ then a constant correction factor of -0.0007 can be used. For lower viscosities a simple power equation was used (Equation 2), which was fit to the experimental data.

$$
f=-2.4979 \cdot 10^{-5} v^{0.61241}
$$

In Equation $2 \mathrm{v}$ is the viscosity of the sample (mPa.s) at the given temperature and pressure. The viscosities of the samples were estimated based on earlier measurements made for other shale fuel oil and dephenolated fuel oil samples. Viscosity correction factors were then calculated and used to adjust the experimental density data measured in this study.

The process of correcting for the viscosity of the sample introduces a small amount of uncertainty to the density data. The largest viscosity correction was $0.72 \mathrm{~kg} \mathrm{~m}^{-3}$ (the smallest was $0.018 \mathrm{~kg} \mathrm{~m}^{-3}$ ). Given that the viscosity correction factor reaches a constant upper value at high viscosities, the added uncertainty is certainly less than $0.72 \mathrm{~kg} \mathrm{~m}^{-3}$. A more reasonable estimate, based on the form of the viscosity correction equation and the expected uncertainty of the estimated viscosity values, is $\pm 0.4 \mathrm{~kg} \mathrm{~m}^{-3}$. That is, it can be expected that most of the density values are within $\pm 0.4 \mathrm{~kg} \mathrm{~m}^{-3}$ of the "true" density value, and this can be taken as the expanded uncertainty of the density data presented here.

\subsubsection{Heat capacity measurements}

Heat capacity temperature dependences were determined between 288 and $423 \mathrm{~K}$ using a micro reaction calorimeter (Thermal Hazard Technology, Bletchley, UK). The instrument was calibrated using heptane (purity $>99 \%$ ) and $\mathrm{Al}_{2} \mathrm{O}_{3}$ (Mettler-Toledo thermal analysis standard). The accuracy of the measurements was assessed by measuring naphthalene (purity $>99 \%$ ). Reference data for all three of these compounds were taken from Sabbah et al. ${ }^{31}$. Based on the measurements with naphthalene, the standard uncertainty was estimated to be $0.015 \mathrm{~J} \mathrm{~g}^{-1} \mathrm{~K}^{-1}$ (expanded uncertainty of $0.032 \mathrm{~J} \mathrm{~g}^{-1} \mathrm{~K}^{-1}$ at the $95 \%$ level). This is a relative expanded uncertainty of about $2 \%$. 


\subsubsection{Measurement of characteristic properties}

An Abbemat HT refractometer (Anton Paar $\mathrm{GmbH}$, Graz, Austria) was used to measure the refractive indexes of the samples at $293 \mathrm{~K}$, and these measurements had a standard uncertainty of 0.0011 (expanded uncertainty of 0.0021 at the $95 \%$ level). This equates to a relative expanded uncertainty of about $0.1 \%$.

Vapor pressure osmometry (Knauer K-7000, Wissenschaftliche Gerätebau Dr. Ing. Herbert KNAUER GmbH, Germany) was used to measure the number average molecular weights of the samples. The standard uncertainty was $7 \mathrm{~g} \mathrm{~mol}^{-1}$ (expanded uncertainty of $14 \mathrm{~g} \mathrm{~mol}^{-1}$ at the $95 \%$ level), which is a relative expanded uncertainty of about $6 \%$.

An Interspec 301-X portable mid-infrared spectrometer (Interspectrum OÜ, Tõravere, Estonia) was used to measure the infrared spectra of the samples. Based on these spectra the hydroxyl group, hydrogen and carbon content were calculated via models that had been created earlier (creation of the models was described in our earlier publications ${ }^{5,24,32}$ ). These models were created using support vector regression. The uncertainties of these predicted values were estimated based on the residuals of the models. The standard uncertainties were $0.35,0.13$ and $0.57 \mathrm{wt} \%$ for hydroxyl group, hydrogen and carbon content, respectively. The expanded uncertainties at the $95 \%$ level were $0.72,0.28$ and $1.3 \mathrm{wt} \%$ (relative expanded uncertainties of 12,3 and $2 \%$ ). The atomic hydrogen-carbon ratio was also calculated from this data (standard uncertainty of 0.016 , expanded uncertainty of 0.033 at the $95 \%$ level).

\subsection{Calculation of thermodynamic properties}

The isothermal expansion coefficient, bulk modulus of compressibility and speed of sound can all be calculated from density data at different temperatures and pressures using basic thermodynamic definitions and relationships. It is important to have data that allows these derived properties to be reliably estimated because they indicate that equations of state, or other models, based on the data can be used for extrapolation.

The thermal expansion coefficient shows how a material expands with changes in temperature, and is defined as shown in Equation $3^{33}$

$$
\alpha \equiv \frac{1}{V}\left(\frac{\partial V}{\partial T}\right)_{P}=\frac{-1}{\rho}\left(\frac{\partial \rho}{\partial T}\right)_{P}
$$

where $\alpha$ is the volumetric thermal expansion coefficient, $\rho$ is density, $V$ is volume, $T$ is temperature and $P$ is pressure. Changes in volume that occur with changes in pressure are often characterized using the isothermal compressibility $(\kappa)$, which is defined by Equation $4 .^{34}$

$$
\kappa \equiv-\frac{1}{V}\left(\frac{\partial V}{\partial P}\right)_{T}=\frac{1}{\rho}\left(\frac{\partial \rho}{\partial P}\right)_{T}
$$

The speed of sound (a) can then be calculated from these properties and the constant pressure heat capacity $\left(C_{P}\right)$ via Equation $5 .^{35,36}$

$$
a=\left(\frac{\partial P}{\partial \rho}\right)_{S}=\sqrt{\frac{C_{P}}{\rho \kappa C_{P}-\alpha^{2} T}}
$$

Here $S$ signifies entropy, and $C_{p}, \rho, \alpha$ and $\kappa$ are at the same temperature and pressure for which the speed of sound is being calculated. Equation 5 and the relationships used in deriving it have been presented in many textbooks. ${ }^{35-39}$ These equations have also been used before by other researchers for calculating the speed of sound or the bulk modulus from density data and vice versa. ${ }^{40}$ 
The experimental density data were fit with a polynomial equation (Equation 6) to describe both the temperature and pressure dependence of the density, and then this equation was used to calculate the necessary partial derivatives. To calculate the heat capacity at the temperatures at which the density data had been measured a linear equation was fit to the experimental heat capacity data (Equations 7 and 8).

\subsection{Uncertainty analysis}

The uncertainty values for the calculated thermodynamic properties were estimated using a Monte Carlo method (see ISO/IEC Guide 98-341). Two variables were varied when determining the uncertainties: density and heat capacity. To describe the uncertainty of the density measurements a Gaussian distribution was used and the standard deviation was specified to be $0.2 \mathrm{~kg} \mathrm{~m}^{-3}$, based on the estimated uncertainty of the measurements and the viscosity correction (see Section 2.3.2). For the uncertainty of the heat capacity a Gaussian distribution was also assumed, and the standard deviation was set to be $0.057 \mathrm{~J}$ $\mathrm{g}^{-1} \mathrm{~K}^{-1}$. This value is slightly higher than the standard measurement uncertainty (see Section 2.3.3), and was chosen to account for the fact that the heat capacity data was extrapolated to higher temperatures (up to $473 \mathrm{~K}$ ) and that the pressure dependence of the heat capacity was not taken into account. The magnitude of this additional uncertainty was based on values for pure compounds obtained from reference equations of state using CoolProp's Excel add-in. ${ }^{28}$ For all of the 9 compounds checked the difference between the heat capacities at 0.1 and $12 \mathrm{MPa}$ was less than $0.035 \mathrm{~J} \mathrm{~g}^{-1} \mathrm{~K}^{-1}$. The pressure dependence of heat capacity is also related to the second derivative of volume with respect to temperature, ${ }^{42}$ and the change in $C_{p}$ with pressure was also estimated from the density data using this relationship. This calculation gave a value that was at least an order of magnitude smaller than the measurement uncertainty. The conservative estimate of $0.035 \mathrm{~J} \mathrm{~g}^{-1} \mathrm{~K}^{-1}$ was used in further uncertainty calculations. To check the effect of extrapolation to higher temperatures the heat capacity at a higher temperature was calculated using a linear fit to values that were at least $50 \mathrm{~K}$ lower. This was done with oxylene, n-undecane and methyl oleate and the difference was always less than $0.042 \mathrm{~J} \mathrm{~g}^{-1}$ $\mathrm{K}^{-1}$. These two uncertainties were then combined with the measurement uncertainty $(0.015$ $\mathrm{J} \mathrm{g}^{-1} \mathrm{~K}^{-1}$ ), which gave the value of $0.057 \mathrm{~J} \mathrm{~g}^{-1} \mathrm{~K}^{-1}$ used in the uncertainty calculations.

These distributions were then sampled (sample size of 2000) and each sample set was used to calculate thermal expansion coefficients, isothermal compressibilities and speeds of sound. With each sample set a separate regression was performed to find the constants to use with Equation 6. This was done to ensure that uncertainty associated with the regression was also taken into account. Using this Monte Carlo method a distribution was obtained for each property at each temperature and pressure. The standard deviation of each distribution was taken to be the standard uncertainty, and the lower and upper confidence limits at the $95 \%$ level were calculated as 2.5 and $97.5 \%$ of the cumulative distribution, respectively.

\section{Results and Discussion}

\subsection{Temperature and pressure dependence of density}

The experimental density data is presented in Table 2 and Table 3 , and has also been graphically presented in Figure 1. The densities measured at atmospheric pressure are also included in these tables, but it should be noted that there is a small difference in the values (about $1 \mathrm{~kg} \mathrm{~m}^{-3}$ ) due to the degassing performed before high pressure measurements. 


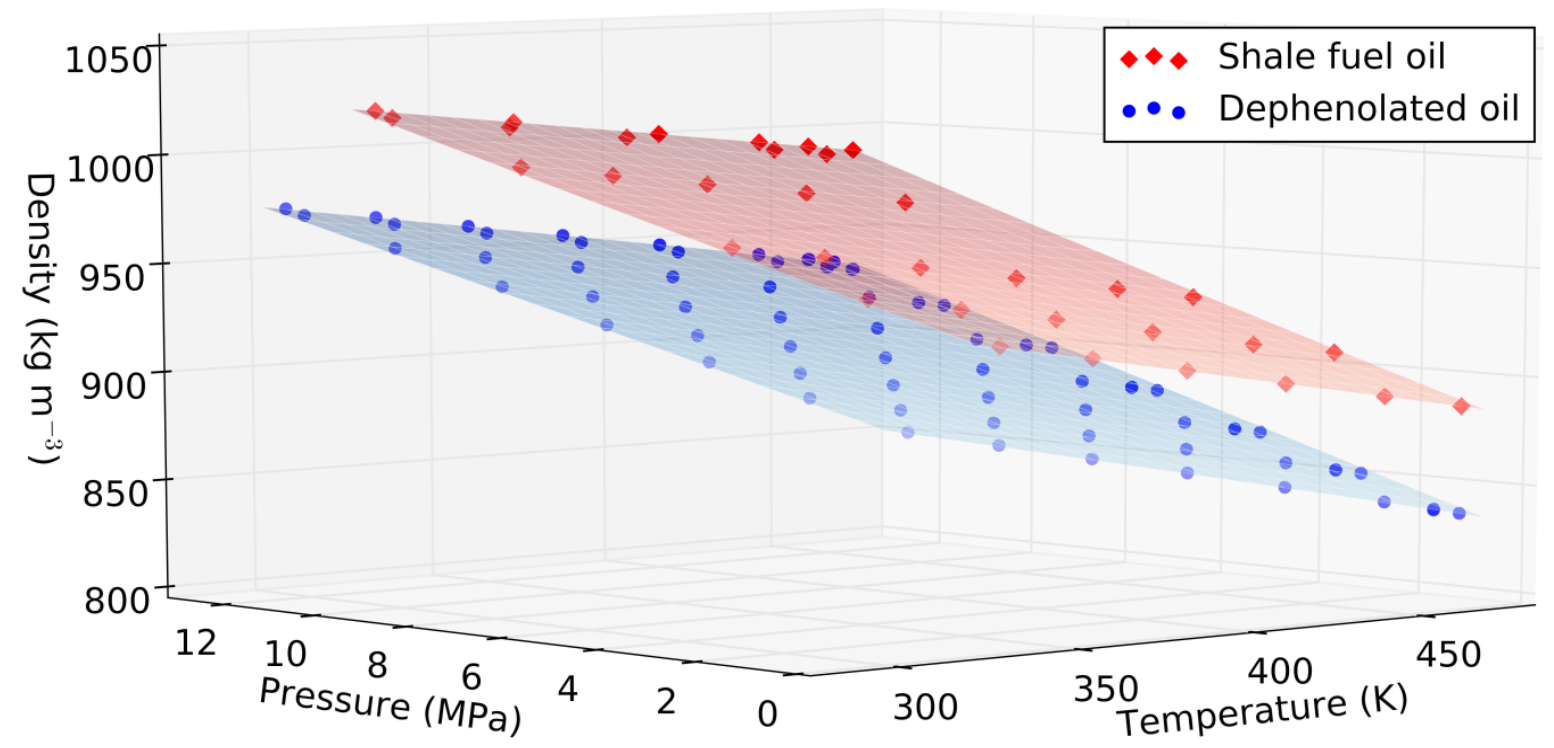

Figure 1. The experimental density data for the shale oil samples.

Table 2. Densities ( $\rho)$, volumetric thermal expansion coefficients $(\alpha)$, isothermal compressibilities $(\kappa)$, and speeds of sound (a) of the shale fuel oil sample along with expanded uncertainties at the 95\% level (u). ${ }^{a}$

\begin{tabular}{|c|c|c|c|c|c|c|c|c|c|}
\hline $\mathbf{T}$ & $\mathbf{P}$ & $\rho$ & $\rho_{\text {calc }}-\rho$ & $\alpha$ & $u(\alpha)$ & K & $u(k)$ & a & $u(a)$ \\
\hline$K$ & $\mathrm{MPa}$ & $\mathrm{kg} \mathrm{m}^{-3}$ & $\mathrm{~kg} \mathrm{~m}^{-3}$ & $K^{-1}$ & $K^{-1}$ & $M P a^{-1}$ & $M P a^{-1}$ & $m s^{-1}$ & $m s^{-1}$ \\
\hline 293.15 & 0.1 & 1017.0 & & & & & & & \\
\hline 293.15 & 0.152 & 1017.9 & 0.0 & $7.36 \cdot 10^{-4}$ & $\pm 3.7 \cdot 10^{-6}$ & $5.1 \cdot 10^{-4}$ & $\pm 8.1 \cdot 10^{-5}$ & 1520 & \pm 79 \\
\hline 293.15 & 1.020 & 1018.3 & 0.1 & $7.33 \cdot 10^{-4}$ & $\pm 3.7 \cdot 10^{-6}$ & $5.1 \cdot 10^{-4}$ & $\pm 6.9 \cdot 10^{-5}$ & 1520 & \pm 130 \\
\hline 293.15 & 1.984 & 1018.9 & 0.0 & $7.29 \cdot 10^{-4}$ & $\pm 3.7 \cdot 10^{-6}$ & $5.0 \cdot 10^{-4}$ & $\pm 5.7 \cdot 10^{-5}$ & 1530 & \pm 70 \\
\hline 293.15 & 3.989 & 1019.9 & 0.0 & $7.23 \cdot 10^{-4}$ & $\pm 3.6 \cdot 10^{-6}$ & $4.9 \cdot 10^{-4}$ & $\pm 3.6 \cdot 1$ & 1550 & \pm 160 \\
\hline 293.16 & 3.990 & 1019.9 & 0.1 & $7.23 \cdot 10^{-4}$ & $\pm 3.6 \cdot 10^{-6}$ & $4.9 \cdot 10^{-4}$ & $\pm 3.6 \cdot 10^{-5}$ & 1550 & \pm 150 \\
\hline 293.15 & 3.992 & 1019.9 & 0.0 & $7.23 \cdot 10^{-4}$ & $\pm 3.6 \cdot 10^{-6}$ & $4.9 \cdot 10^{-4}$ & $\pm 3.6 \cdot 10^{-5}$ & 1550 & \pm 100 \\
\hline 293.15 & 6.984 & 1021.4 & 0.0 & $7.13 \cdot 10^{-4}$ & $\pm 3.7 \cdot 10^{-6}$ & $4.7 \cdot 10^{-4}$ & & & \pm 69 \\
\hline 293.15 & 9.929 & 1022.9 & 0.0 & $7.03 \cdot 10^{-4}$ & $\pm 4.0 \cdot 10^{-6}$ & $4.6 \cdot 10^{-4}$ & \pm 7.4 & 1600 & \pm 68 \\
\hline 298.15 & 1.022 & 1014 & 0.0 & $7.34 \cdot 10^{-4}$ & $\pm 3.5 \cdot 10^{-6}$ & $5.2 \cdot 10^{-4}$ & & & \\
\hline 298.15 & 2.051 & 1015.2 & 0.1 & $7.31 \cdot 10^{-4}$ & $\pm 3.4 \cdot 10^{-6}$ & $5.2 \cdot 10^{-4}$ & \pm 5.6 & 1510 & \pm 97 \\
\hline 298.15 & 5.019 & 101 & -0.1 & $7.21 \cdot 10^{-4}$ & $\pm 3.4 \cdot 1$ & $5.0 \cdot 1$ & \pm 3.0 & 1530 & \pm 150 \\
\hline 298.15 & 7.452 & 1018.1 & 0.0 & $7.13 \cdot 10$ & $\pm 3.5 \cdot 10^{-6}$ & $4.9 \cdot 1$ & \pm 4.3 & 1550 & \pm 120 \\
\hline 298.15 & 9.962 & 1019.3 & -0.1 & $7.05 \cdot 10^{-4}$ & $\pm 3.8 \cdot 10^{-6}$ & $4.7 \cdot 10^{-4}$ & $\pm 7.4 \cdot 10^{-5}$ & 1570 & \pm 83 \\
\hline & & 1002 & & & & & & & \\
\hline 333.15 & & & & & & & & & \\
\hline 333.15 & 1.996 & 989.5 & -0.1 & $7.44 \cdot 10^{-4}$ & $\pm 2.3 \cdot 10^{-6}$ & $6.4 \cdot 10^{-4}$ & & & \pm 70 \\
\hline 333.15 & 3.970 & & -0.1 & $7.37 \cdot 10^{-4}$ & $\pm 2.2 \cdot 10^{-6}$ & $6.3 \cdot 10^{-4}$ & & 1370 & \pm 40 \\
\hline 333.15 & 5.992 & 991.9 & 0.0 & $7.30 \cdot 10^{-4}$ & $\pm 2.2 \cdot 10^{-6}$ & $6.2 \cdot 10^{-4}$ & $\pm 2.5 \cdot 10^{-5}$ & 1390 & \pm 110 \\
\hline 333.15 & 7.965 & 993.1 & 0.0 & $7.23 \cdot 10^{-4}$ & $\pm 2.4 \cdot 10^{-6}$ & $6.0 \cdot 10^{-4}$ & $\pm 4.6 \cdot 10^{-5}$ & 1400 & \pm 64 \\
\hline 333.15 & 9.931 & 994.2 & -0.1 & $7.16 \cdot 10^{-4}$ & $\pm 2.7 \cdot 10^{-6}$ & $5.9 \cdot 10^{-4}$ & $\pm 7.2 \cdot 10^{-5}$ & 1410 & \pm 35 \\
\hline 353.15 & 0.1 & 973.3 & & & & & & & \\
\hline 393.15 & 0.516 & 944.4 & -0.1 & $7.72 \cdot 10^{-4}$ & $\pm 1.9 \cdot 10^{-6}$ & $8.7 \cdot 10^{-4}$ & $\pm 7.8 \cdot 10^{-5}$ & 1180 & \pm 46 \\
\hline 393.15 & 1.993 & 945.6 & 0.1 & $7.67 \cdot 10^{-4}$ & $\pm 1.6 \cdot 10^{-6}$ & $8.6 \cdot 10^{-4}$ & $\pm 5.5 \cdot 10^{-5}$ & 1190 & \pm 41 \\
\hline
\end{tabular}




\begin{tabular}{l|l|llllllll}
393.15 & 4.006 & 947.2 & 0.0 & $7.59 \cdot 10^{-4}$ & $\pm 1.3 \cdot 10^{-6}$ & $8.5 \cdot 10^{-4}$ & $\pm 2.9 \cdot 10^{-5}$ & 1200 & \pm 25 \\
393.15 & 5.958 & 948.7 & -0.1 & $7.51 \cdot 10^{-4}$ & $\pm 1.3 \cdot 10^{-6}$ & $8.4 \cdot 10^{-4}$ & $\pm 2.5 \cdot 10^{-5}$ & 1200 & \pm 62 \\
393.15 & 7.956 & 950.2 & 0.0 & $7.44 \cdot 10^{-4}$ & $\pm 1.6 \cdot 10^{-6}$ & $8.2 \cdot 10^{-4}$ & $\pm 4.6 \cdot 10^{-5}$ & 1210 & \pm 21 \\
393.16 & 9.929 & 951.7 & 0.2 & $7.36 \cdot 10^{-4}$ & $\pm 2.1 \cdot 10^{-6}$ & $8.1 \cdot 10^{-4}$ & $\pm 7.4 \cdot 10^{-5}$ & 1220 & \pm 68 \\
433.15 & 0.419 & 915.7 & 0.3 & $7.89 \cdot 10^{-4}$ & $\pm 3.3 \cdot 10^{-6}$ & $1.03 \cdot 10^{-3}$ & $\pm 8.3 \cdot 10^{-5}$ & 1100 & \pm 54 \\
433.16 & 1.995 & 916.4 & 0.1 & $7.83 \cdot 10^{-4}$ & $\pm 3.1 \cdot 10^{-6}$ & $1.02 \cdot 10^{-3}$ & $\pm 6.0 \cdot 10^{-5}$ & 1100 & \pm 23 \\
433.15 & 4.001 & 918.4 & -0.4 & $7.74 \cdot 10^{-4}$ & $\pm 2.9 \cdot 10^{-6}$ & $1.01 \cdot 10^{-3}$ & $\pm 3.6 \cdot 10^{-5}$ & 1110 & \pm 21 \\
433.15 & 5.965 & 920.8 & -0.4 & $7.66 \cdot 10^{-4}$ & $\pm 2.9 \cdot 10^{-6}$ & $9.9 \cdot 10^{-4}$ & $\pm 3.1 \cdot 10^{-5}$ & 1120 & \pm 52 \\
433.15 & 7.943 & 921.9 & 0.3 & $7.58 \cdot 10^{-4}$ & $\pm 2.9 \cdot 10^{-6}$ & $9.8 \cdot 10^{-4}$ & $\pm 5.1 \cdot 10^{-5}$ & 1120 & \pm 36 \\
433.15 & 9.924 & 923.7 & 0.3 & $7.50 \cdot 10^{-4}$ & $\pm 3.3 \cdot 10^{-6}$ & $9.7 \cdot 10^{-4}$ & $\pm 7.8 \cdot 10^{-5}$ & 1130 & \pm 38 \\
473.15 & 0.515 & 886.4 & 0.2 & $8.06 \cdot 10^{-4}$ & $\pm 5.3 \cdot 10^{-6}$ & $1.20 \cdot 10^{-3}$ & $\pm 8.8 \cdot 10^{-5}$ & 1030 & \pm 34 \\
473.15 & 2.010 & 888.0 & 0.2 & $8.00 \cdot 10^{-4}$ & $\pm 5.1 \cdot 10^{-6}$ & $1.19 \cdot 10^{-3}$ & $\pm 6.6 \cdot 10^{-5}$ & 1040 & \pm 44 \\
473.16 & 3.979 & 890.1 & -0.1 & $7.91 \cdot 10^{-4}$ & $\pm 4.9 \cdot 10^{-6}$ & $1.18 \cdot 10^{-3}$ & $\pm 4.7 \cdot 10^{-5}$ & 1040 & \pm 22 \\
473.15 & 5.985 & 892.4 & -0.3 & $7.82 \cdot 10^{-4}$ & $\pm 5.0 \cdot 10^{-6}$ & $1.16 \cdot 10^{-3}$ & $\pm 4.3 \cdot 10^{-5}$ & 1050 & \pm 47 \\
473.15 & 7.951 & 894.5 & -0.2 & $7.74 \cdot 10^{-4}$ & $\pm 5.0 \cdot 10^{-6}$ & $1.15 \cdot 10^{-3}$ & $\pm 6.0 \cdot 10^{-5}$ & 1050 & \pm 32 \\
\hline 473.15 & 9.925 & 896.7 & 0.1 & $7.65 \cdot 10^{-4}$ & $\pm 5.1 \cdot 10^{-6}$ & $1.13 \cdot 10^{-3}$ & $\pm 8.5 \cdot 10^{-5}$ & 1050 & \pm 23 \\
\hline
\end{tabular}

${ }^{a}$ Standard uncertainty \{and expanded uncertainty at $95 \%$ level\}: pressure $= \pm 0.0031\{0.0063\} \mathrm{MPa}$, density $= \pm 0.2\{0.4\}$ $\mathrm{kg} \mathrm{m}^{-3}$, density at atmospheric pressure $= \pm 0.15\{0.3\} \mathrm{kg} \mathrm{m}^{-3}$.

${ }^{\mathrm{b}}$ Deviation between density calculated using Equation 6 and the experimentally determined density.

Table 3. Densities ( $\rho$ ), volumetric thermal expansion coefficients $(\alpha)$, isothermal compressibilities $(\kappa)$, and speeds of sound (a) of the dephenolated shale fuel oil sample along with expanded uncertainties at the $95 \%$ level $(u){ }^{a}$

\begin{tabular}{|c|c|c|c|c|c|c|c|c|c|}
\hline $\mathbf{T}$ & $\mathbf{P}$ & $\rho$ & $\rho_{\text {calc }}-\rho$ & $\alpha$ & $u(\alpha)$ & K & $u(k)$ & a & $u(a)$ \\
\hline$K$ & $M P a$ & $\mathrm{~kg} \mathrm{~m}^{-3}$ & $\mathrm{~kg} \mathrm{~m}^{-3}$ & $K^{-1}$ & $K^{-1}$ & $M P a^{-1}$ & $M P a^{-1}$ & $m s^{-1}$ & $m s^{-1}$ \\
\hline 293.15 & 0.1 & 968.2 & & & & & & & \\
\hline 293.15 & 0.518 & 969.5 & 0.2 & $7.53 \cdot 10^{-4}$ & $\pm 2.7 \cdot 10^{-6}$ & $5.8 \cdot 10^{-4}$ & $\pm 4.6 \cdot 10^{-5}$ & 1460 & \pm 68 \\
\hline 293.16 & 1.007 & 969.8 & 0.1 & $7.51 \cdot 10^{-4}$ & $\pm 2.6 \cdot 10^{-6}$ & $5.8 \cdot 10^{-4}$ & $\pm 4.2 \cdot 10^{-5}$ & 1460 & \pm 55 \\
\hline 293.15 & 1.025 & 969.8 & 0.1 & $7.50 \cdot 10^{-4}$ & $\pm 2.7 \cdot 10^{-6}$ & $5.8 \cdot 10^{-4}$ & $\pm 4.2 \cdot 10^{-5}$ & 1460 & \pm 39 \\
\hline 293.15 & 1.995 & 970.3 & 0.0 & $7.46 \cdot 10^{-4}$ & $\pm 2.6 \cdot 10^{-6}$ & $5.6 \cdot 10^{-4}$ & $\pm 3.5 \cdot 10^{-5}$ & 1480 & \pm 33 \\
\hline 293.15 & 3.982 & 971.4 & 0.0 & $7.38 \cdot 10^{-4}$ & $\pm 2.6 \cdot 10^{-6}$ & $5.4 \cdot 10^{-4}$ & $\pm 2.4 \cdot 10^{-5}$ & 1510 & \pm 48 \\
\hline 293.15 & 5.970 & 972.5 & -0.1 & $7.29 \cdot 10^{-4}$ & $\pm 2.6 \cdot 10^{-6}$ & $5.2 \cdot 10^{-4}$ & $\pm 1.9 \cdot 10^{-5}$ & 1540 & \pm 79 \\
\hline 293.15 & 7.957 & 973.6 & -0.2 & $7.21 \cdot 10^{-4}$ & $\pm 2.6 \cdot 10^{-6}$ & $5.0 \cdot 10^{-4}$ & $\pm 2.5 \cdot 10^{-5}$ & 1570 & \pm 120 \\
\hline 293.15 & 9.941 & 974.6 & 0.2 & $7.13 \cdot 10^{-4}$ & $\pm 2.8 \cdot 10^{-6}$ & $4.8 \cdot 10^{-4}$ & $\pm 3.7 \cdot 10^{-5}$ & 1610 & \pm 64 \\
\hline 293.15 & 11.922 & 975.6 & 0.2 & $7.05 \cdot 10^{-4}$ & $\pm 2.9 \cdot 10^{-6}$ & $4.6 \cdot 10^{-4}$ & $\pm 5.1 \cdot 10^{-5}$ & 1650 & \pm 66 \\
\hline 298.15 & 0.510 & 965.9 & 0.2 & $7.56 \cdot 10^{-4}$ & $\pm 2.5 \cdot 10^{-6}$ & $6.0 \cdot 10^{-4}$ & $\pm 4.7 \cdot 10^{-5}$ & 1430 & \pm 63 \\
\hline 298.15 & 0.511 & 965.9 & 0.1 & $7.56 \cdot 10^{-4}$ & $\pm 2.5 \cdot 10^{-6}$ & $6.0 \cdot 10^{-4}$ & $\pm 4.6 \cdot 10^{-5}$ & 1430 & \pm 60 \\
\hline 298.15 & 0.528 & 965.9 & 0.1 & $7.56 \cdot 10^{-4}$ & $\pm 2.6 \cdot 10^{-6}$ & $6.0 \cdot 10^{-4}$ & $\pm 4.6 \cdot 10^{-5}$ & 1430 & \pm 60 \\
\hline 298.15 & 1.005 & 966.1 & 0.1 & $7.54 \cdot 10^{-4}$ & $\pm 2.6 \cdot 10^{-6}$ & $6.0 \cdot 10^{-4}$ & $\pm 4.2 \cdot 10^{-5}$ & 1440 & \pm 65 \\
\hline 298.15 & 1.024 & 966.2 & 0.1 & $7.54 \cdot 10^{-4}$ & $\pm 2.5 \cdot 10^{-6}$ & $6.0 \cdot 10^{-4}$ & $\pm 4.2 \cdot 10^{-5}$ & 1440 & \pm 64 \\
\hline 298.15 & 1.990 & 966.8 & 0.1 & $7.50 \cdot 10^{-4}$ & $\pm 2.4 \cdot 10^{-6}$ & $5.9 \cdot 10^{-4}$ & $\pm 3.5 \cdot 10^{-5}$ & 1450 & \pm 52 \\
\hline 298.15 & 3.980 & 967.9 & 0.1 & $7.41 \cdot 10^{-4}$ & $\pm 2.5 \cdot 10^{-6}$ & $5.6 \cdot 10^{-4}$ & $\pm 2.4 \cdot 10^{-5}$ & 1480 & \pm 36 \\
\hline 298.15 & 5.969 & 969.0 & 0.0 & $7.33 \cdot 10^{-4}$ & $\pm 2.5 \cdot 10^{-6}$ & $5.4 \cdot 10^{-4}$ & $\pm 1.8 \cdot 10^{-5}$ & 1510 & \pm 30 \\
\hline 298.15 & 7.956 & 970.1 & 0.0 & $7.24 \cdot 10^{-4}$ & $\pm 2.5 \cdot 10^{-6}$ & $5.2 \cdot 10^{-4}$ & $\pm 2.4 \cdot 10^{-5}$ & 1540 & \pm 45 \\
\hline 298.15 & 9.939 & 971.1 & -0.1 & $7.16 \cdot 10^{-4}$ & $\pm 2.7 \cdot 10^{-6}$ & $5.0 \cdot 10^{-4}$ & $\pm 3.7 \cdot 10^{-5}$ & 1580 & \pm 72 \\
\hline 298.15 & 11.919 & 972.2 & -0.2 & $7.08 \cdot 10^{-4}$ & $\pm 2.8 \cdot 10^{-6}$ & $4.8 \cdot 10^{-4}$ & $\pm 5.2 \cdot 10^{-5}$ & 1610 & \pm 110 \\
\hline 313.15 & 0.1 & 954.2 & & & & & & & \\
\hline 323.16 & 0.524 & 947.8 & -0.1 & $7.72 \cdot 10^{-4}$ & $\pm 2.0 \cdot 10^{-6}$ & $7.1 \cdot 10^{-4}$ & $\pm 4.6 \cdot 10^{-5}$ & 1320 & \pm 26 \\
\hline 323.16 & 1.019 & 948.2 & -0.1 & $7.70 \cdot 10^{-4}$ & $\pm 2.0 \cdot 10^{-6}$ & $7.1 \cdot 10^{-4}$ & $\pm 4.3 \cdot 10^{-5}$ & 1330 & \pm 46 \\
\hline
\end{tabular}




\begin{tabular}{|c|c|c|c|c|c|c|c|c|c|}
\hline 323.15 & 1.024 & 948.2 & 0.0 & $7.70 \cdot 10^{-4}$ & $\pm 1.9 \cdot 10^{-6}$ & $7.1 \cdot 10^{-4}$ & $\pm 4.3 \cdot 10^{-5}$ & 1330 & \pm 20 \\
\hline 323.15 & 1.995 & 948.8 & 0.0 & $7.66 \cdot 10^{-4}$ & $\pm 1.9 \cdot 10^{-6}$ & $7.0 \cdot 10^{-4}$ & $\pm 3.5 \cdot 10^{-5}$ & 1340 & \pm 31 \\
\hline 23.15 & 3.980 & 950.1 & 0.0 & $7.57 \cdot 10^{-4}$ & $\pm 1.9 \cdot 10^{-6}$ & $6.7 \cdot 10^{-4}$ & $\pm 2.1 \cdot 10^{-5}$ & 1360 & \pm 52 \\
\hline 323.15 & 5.968 & 951.3 & 0.0 & $7.48 \cdot 10^{-4}$ & $\pm 1.9 \cdot 10^{-6}$ & $6.5 \cdot 10^{-4}$ & $\pm 1.5 \cdot 10^{-5}$ & 1380 & \pm 76 \\
\hline 323.15 & 7.956 & 952.5 & -0.1 & $7.40 \cdot 10^{-4}$ & $\pm 1.9 \cdot 10^{-6}$ & $6.3 \cdot 10^{-4}$ & $\pm 2.2 \cdot 10^{-5}$ & 1410 & \pm 39 \\
\hline 323.15 & 9.941 & 953.7 & -0.1 & $7.31 \cdot 10^{-4}$ & $\pm 2.1 \cdot 10^{-6}$ & $6.1 \cdot 10^{-4}$ & $\pm 3.7 \cdot 10^{-5}$ & 1430 & \pm 46 \\
\hline 323.15 & 11.920 & 954.8 & -0.1 & $7.22 \cdot 10^{-4}$ & $\pm 2.3 \cdot 10^{-6}$ & $5.8 \cdot 10^{-4}$ & $\pm 5.2 \cdot 10^{-5}$ & 1460 & \pm 51 \\
\hline 333.15 & 0.1 & 939.9 & & & & & & & \\
\hline 53.15 & 0.1 & 925.4 & & & & & & & \\
\hline 353.16 & 0.527 & 926.1 & -0.3 & $7.93 \cdot 10^{-4}$ & $\pm 1.4 \cdot 10^{-6}$ & $8.5 \cdot 10^{-4}$ & $\pm 4.7 \cdot 10^{-5}$ & 1220 & \pm 36 \\
\hline 353.15 & 1.023 & 926.4 & 0.0 & $7.91 \cdot 10^{-4}$ & $\pm 1.4 \cdot 10^{-6}$ & $8.4 \cdot 10^{-4}$ & $\pm 4.3 \cdot 10^{-5}$ & 1220 & \pm 56 \\
\hline 353.16 & 1.024 & 926.4 & -0.2 & $7.91 \cdot 10^{-4}$ & $\pm 1.3 \cdot 10^{-6}$ & $8.4 \cdot 10^{-4}$ & $\pm 4.3 \cdot 10^{-5}$ & 1220 & \pm 13 \\
\hline 353.15 & 1.994 & 927.2 & -0.1 & $7.86 \cdot 10^{-4}$ & $\pm 1.3 \cdot 10^{-6}$ & $8.3 \cdot 10^{-4}$ & $\pm 3.5 \cdot 10^{-5}$ & 1230 & \pm 22 \\
\hline 353.15 & 3.981 & 928.6 & 0.0 & $7.77 \cdot 10^{-4}$ & $\pm 1.2 \cdot 10^{-6}$ & $8.1 \cdot 10^{-4}$ & $\pm 2.1 \cdot 10^{-5}$ & 1250 & \pm 38 \\
\hline 353.15 & 5.968 & 930.0 & -0.2 & $7.68 \cdot 10^{-4}$ & $\pm 1.2 \cdot 10^{-6}$ & $7.9 \cdot 10^{-4}$ & $\pm 1.3 \cdot 10^{-5}$ & 1260 & \pm 19 \\
\hline 353.15 & 7.953 & 931.4 & -0.3 & $7.59 \cdot 10^{-4}$ & $\pm 1.3 \cdot 10^{-6}$ & $7.6 \cdot 10^{-4}$ & $\pm 2.1 \cdot 10^{-5}$ & 1280 & \pm 29 \\
\hline 353.15 & 9.938 & 932.7 & -0.4 & $7.50 \cdot 10^{-4}$ & $\pm 1.5 \cdot 10^{-6}$ & $7.4 \cdot 10^{-4}$ & $\pm 3.7 \cdot 10^{-5}$ & 1300 & \pm 39 \\
\hline 353.15 & 11.918 & 934.0 & -0.3 & $7.41 \cdot 10^{-4}$ & $\pm 1.8 \cdot 10^{-6}$ & $7.2 \cdot 10^{-4}$ & $\pm 5.3 \cdot 10^{-5}$ & 1320 & \pm 36 \\
\hline 383.15 & 0.525 & 903.8 & -0.2 & $8.15 \cdot 10^{-4}$ & $\pm 1.2 \cdot 10^{-6}$ & $9.9 \cdot 10^{-4}$ & $\pm 4.7 \cdot 10^{-5}$ & 1140 & \pm 32 \\
\hline 383.15 & 1.023 & 904.2 & -0.1 & $8.13 \cdot 10^{-4}$ & $\pm 1.1 \cdot 10^{-6}$ & $9.9 \cdot 10^{-4}$ & $\pm 4.4 \cdot 10^{-5}$ & 1140 & \pm 24 \\
\hline 383.16 & 1.024 & 904.3 & 0.0 & $8.13 \cdot 10^{-4}$ & $\pm 1.1 \cdot 10^{-6}$ & $9.9 \cdot 10^{-4}$ & $\pm 4.3 \cdot 10^{-5}$ & 1140 & \pm 15 \\
\hline 383.15 & 1.994 & 905.1 & 0.1 & $8.08 \cdot 10^{-4}$ & $\pm 1.0 \cdot 10^{-6}$ & $9.8 \cdot 10^{-4}$ & $\pm 3.5 \cdot 1$ & 140 & \pm 10 \\
\hline 383.15 & 3.978 & 906.7 & 0.1 & $7.98 \cdot 10^{-4}$ & $\pm 8.7 \cdot 10^{-7}$ & $9.5 \cdot 10^{-4}$ & $\pm 2.1 \cdot 10^{-5}$ & 1160 & \pm 18 \\
\hline 383.15 & 5.967 & 908.3 & -0.1 & $7.89 \cdot 10^{-4}$ & $\pm 9.1 \cdot 10^{-7}$ & $9.3 \cdot 10^{-4}$ & $\pm 1.3 \cdot 10^{-5}$ & 1170 & \pm 29 \\
\hline 383.15 & 7.955 & 909.9 & 0.2 & $7.79 \cdot 10^{-4}$ & $\pm 1.1 \cdot 10^{-6}$ & $9.0 \cdot 10^{-4}$ & $\pm 2.2 \cdot 10^{-5}$ & 1190 & \pm 29 \\
\hline 383.15 & 9.938 & 911.5 & 0.3 & $7.70 \cdot 10^{-4}$ & $\pm 1.4 \cdot 10^{-6}$ & $8.8 \cdot 10^{-4}$ & $\pm 3.7 \cdot 10^{-5}$ & 1200 & \pm 44 \\
\hline 383.15 & 11.918 & 912.9 & -0.2 & $7.60 \cdot 10^{-4}$ & $\pm 1.6 \cdot 10^{-6}$ & $8.6 \cdot 10^{-4}$ & $\pm 5.4 \cdot 10^{-5}$ & 1220 & \pm 29 \\
\hline 413.16 & 0.527 & 881.6 & 0.2 & $8.38 \cdot 10^{-4}$ & $\pm 1.7 \cdot 10^{-6}$ & $1.15 \cdot 10^{-3}$ & $\pm 4.9 \cdot 10^{-5}$ & 1070 & \pm 11 \\
\hline 413.15 & 1.022 & 882.0 & 0.2 & $8.36 \cdot 10^{-4}$ & $\pm 1.6 \cdot 10^{-6}$ & $1.14 \cdot 10^{-3}$ & $\pm 4.5 \cdot 10^{-5}$ & 1070 & \pm 16 \\
\hline 413.16 & 1.022 & 882.1 & 0.3 & $8.36 \cdot 10^{-4}$ & $\pm 1.6 \cdot 10^{-6}$ & $1.14 \cdot 10^{-3}$ & $\pm 4.5 \cdot 10^{-5}$ & 1070 & \pm 24 \\
\hline 413.15 & 2.004 & 883.0 & 0.4 & $8.31 \cdot 10^{-4}$ & $\pm 1.5 \cdot 10^{-6}$ & $1.13 \cdot 10^{-3}$ & $\pm 3.7 \cdot 10^{-5}$ & 1080 & \pm 35 \\
\hline 413.14 & 3.980 & 884.9 & 0.1 & $8.20 \cdot 10^{-4}$ & $\pm 1.4 \cdot 10^{-6}$ & $1.10 \cdot 10^{-3}$ & $\pm 2.2 \cdot 10^{-5}$ & 1090 & \pm 14 \\
\hline 413.14 & 5.966 & 886.7 & 0.0 & $8.10 \cdot 10^{-4}$ & $\pm 1.4 \cdot 10^{-6}$ & $1.08 \cdot 10^{-3}$ & $\pm 1.5 \cdot 10^{-5}$ & 1100 & \pm 25 \\
\hline 413.14 & 7.952 & 888.5 & 0.0 & $8.00 \cdot 10^{-4}$ & $\pm 1.6 \cdot 10^{-6}$ & $1.05 \cdot 10^{-3}$ & $\pm 2.4 \cdot 10^{-5}$ & 1110 & \pm 21 \\
\hline 413.14 & 9.937 & 890.3 & -0.1 & $7.90 \cdot 10^{-4}$ & $\pm 1.8 \cdot 10^{-6}$ & $1.03 \cdot 10^{-3}$ & $\pm 4.0 \cdot 10^{-5}$ & 1120 & \pm 27 \\
\hline 413.14 & 11.917 & 892.0 & -0.1 & $7.81 \cdot 10^{-4}$ & $\pm 2.0 \cdot 10^{-6}$ & $1.00 \cdot 10^{-3}$ & $\pm 5.6 \cdot 10^{-5}$ & 1130 & \pm 25 \\
\hline 443.16 & 0.525 & 859.2 & 0.2 & $8.63 \cdot 10^{-4}$ & $\pm 2.6 \cdot 10^{-6}$ & $1.31 \cdot 10^{-3}$ & $\pm 5.2 \cdot 10^{-5}$ & 1010 & \pm 22 \\
\hline 443.15 & 1.013 & 859.7 & 0.1 & $8.60 \cdot 10^{-4}$ & $\pm 2.5 \cdot 10^{-6}$ & $1.30 \cdot 10^{-3}$ & $\pm 4.8 \cdot 10^{-5}$ & 1010 & \pm 22 \\
\hline 443.15 & 1.020 & 859.8 & 0.2 & $8.60 \cdot 10^{-4}$ & $\pm 2.5 \cdot 10^{-6}$ & $1.30 \cdot 10^{-3}$ & $\pm 4.7 \cdot 10^{-5}$ & 1010 & \pm 30 \\
\hline 443.16 & 1.994 & 860.9 & 0.2 & $8.55 \cdot 10^{-4}$ & $\pm 2.5 \cdot 10^{-6}$ & $1.29 \cdot 10^{-3}$ & $\pm 3.9 \cdot 10^{-5}$ & 1020 & \pm 14 \\
\hline 443.15 & 3.979 & 863.0 & 0.2 & $8.44 \cdot 10^{-4}$ & $\pm 2.4 \cdot 10^{-6}$ & $1.26 \cdot 10^{-3}$ & $\pm 2.6 \cdot 10^{-5}$ & 1030 & \pm 22 \\
\hline 443.15 & 5.966 & 865.1 & 0.1 & $8.33 \cdot 10^{-4}$ & $\pm 2.4 \cdot 10^{-6}$ & $1.23 \cdot 10^{-3}$ & $\pm 2.0 \cdot 10^{-5}$ & 1040 & \pm 13 \\
\hline 443.15 & 7.953 & 867.2 & 0.2 & $8.23 \cdot 10^{-4}$ & $\pm 2.4 \cdot 10^{-6}$ & $1.21 \cdot 10^{-3}$ & $\pm 2.8 \cdot 10^{-5}$ & 1050 & \pm 11 \\
\hline 443.15 & 9.937 & 869.3 & 0.1 & $8.12 \cdot 10^{-4}$ & $\pm 2.6 \cdot 10^{-6}$ & $1.18 \cdot 10^{-3}$ & $\pm 4.2 \cdot 10^{-5}$ & 1060 & \pm 19 \\
\hline 443.15 & 11.915 & 871.2 & 0.1 & $8.02 \cdot 10^{-4}$ & $\pm 2.7 \cdot 10^{-6}$ & $1.15 \cdot 10^{-3}$ & $\pm 5.8 \cdot 10^{-5}$ & 1070 & \pm 24 \\
\hline 473.16 & 0.529 & 836.9 & -0.4 & $8.88 \cdot 10^{-4}$ & $\pm 3.7 \cdot 10^{-6}$ & $1.47 \cdot 10^{-3}$ & $\pm 5.5 \cdot 10^{-5}$ & 970 & \pm 14 \\
\hline 473.15 & 1.026 & 837.7 & -0.2 & $8.85 \cdot 10^{-4}$ & $\pm 3.6 \cdot 10^{-6}$ & $1.47 \cdot 10^{-3}$ & $\pm 5.1 \cdot 10^{-5}$ & 970 & \pm 11 \\
\hline 473.15 & 1.030 & 837.3 & 0.0 & $8.85 \cdot 10^{-4}$ & $\pm 3.7 \cdot 10^{-6}$ & $1.47 \cdot 10^{-3}$ & $\pm 5.1 \cdot 10^{-5}$ & 970 & \pm 20 \\
\hline
\end{tabular}




\begin{tabular}{l|c|cccccccc}
473.15 & 1.997 & 838.9 & 0.4 & $8.80 \cdot 10^{-4}$ & $\pm 3.5 \cdot 10^{-6}$ & $1.45 \cdot 10^{-3}$ & $\pm 4.4 \cdot 10^{-5}$ & 970 & \pm 20 \\
473.15 & 3.980 & 841.4 & -0.1 & $8.69 \cdot 10^{-4}$ & $\pm 3.5 \cdot 10^{-6}$ & $1.42 \cdot 10^{-3}$ & $\pm 3.2 \cdot 10^{-5}$ & 980 & \pm 13 \\
473.14 & 5.969 & 843.9 & -0.5 & $8.57 \cdot 10^{-4}$ & $\pm 3.5 \cdot 10^{-6}$ & $1.40 \cdot 10^{-3}$ & $\pm 2.6 \cdot 10^{-5}$ & 990 & \pm 19 \\
473.14 & 7.955 & 846.3 & -0.5 & $8.46 \cdot 10^{-4}$ & $\pm 3.5 \cdot 10^{-6}$ & $1.37 \cdot 10^{-3}$ & $\pm 3.2 \cdot 10^{-5}$ & 990 & \pm 26 \\
473.15 & 9.938 & 848.7 & 0.0 & $8.35 \cdot 10^{-4}$ & $\pm 3.6 \cdot 10^{-6}$ & $1.34 \cdot 10^{-3}$ & $\pm 4.6 \cdot 10^{-5}$ & 1000 & \pm 18 \\
\hline 473.15 & 11.918 & 851.0 & 0.1 & $8.24 \cdot 10^{-4}$ & $\pm 3.7 \cdot 10^{-6}$ & $1.31 \cdot 10^{-3}$ & $\pm 6.2 \cdot 10^{-5}$ & 1010 & \pm 22 \\
\hline
\end{tabular}

a Standard uncertainty \{and expanded uncertainty at $95 \%$ level\}: pressure $= \pm 0.0031\{0.0063\} \mathrm{MPa}$, density $= \pm 0.2\{0.4\}$ $\mathrm{kg} \mathrm{m}^{-3}$, density at atmospheric pressure $= \pm 0.15\{0.3\} \mathrm{kg} \mathrm{m}^{-3}$.

${ }^{\mathrm{b}}$ Deviation between density calculated using Equation 6 and the experimentally determined density.

As seen by comparison of the two surfaces, the density noticeably decreases when phenolic compounds are removed. At a constant pressure, the change in the density with temperature was essentially linear to within the measurement accuracy of the data. Linear equations fit to the constant pressure data had $R^{2}$ values greater than 0.999 . The same was true of the pressure dependence at a constant temperature.

To be able to fit the data as a function of both temperature and pressure a polynomial equation (Equation 6) was used.

$$
\rho=A+B \cdot T+C \cdot P+D \cdot P^{2}+E \cdot T \cdot P+F \cdot T^{2}
$$

In Equation 6, $\rho$ is the density $\left(\mathrm{kg} \mathrm{m}^{-3}\right), T$ is the temperature $(\mathrm{K}), P$ is the pressure (bar) and $A$ through $F$ are empirical constants. The constants used for each sample are shown in Table 4. This equation is valid for temperatures from 293.15 to $473.15 \mathrm{~K}$ and pressures from 0.1 to $10 \mathrm{MPa}$ ( 0.1 to $12 \mathrm{MPa}$ for the dephenolated sample). These constants were found by minimizing the root mean squared error (RMSE) of Equation 6 using the differential evolution solver ${ }^{43}$ implemented in the SciPy package ${ }^{44}$ for Python. The data at atmospheric pressure were not included when fitting Equation 6 because there was a slight difference between the datasets due to degassing. When using Equation 6 the RMSE for the fuel oil was $0.17 \mathrm{~kg} \mathrm{~m}^{-3}$ and $0.18 \mathrm{~kg} \mathrm{~m}^{-3}$ for the dephenolated fuel oil. The residual for each data point are given in the fourth column of Table 2 and Table 3. A polynomial equation was used because it is simple, but still provided an accurate fit of the data. This form of the polynomial equation was used because simpler polynomials gave somewhat poorer fits. A more complicated polynomial with more terms was also tested, but the uncertainty of the partial derivatives calculated using this equation were higher. Additionally, it was worried that the higher order polynomial overfit the data. Partial derivatives of Equation 6 were later used for calculating additional thermodynamic properties.

Table 4. Constants used with Equation 6 for estimating the density as a function of temperature and pressure.

\begin{tabular}{l|cc}
\multicolumn{1}{c}{ Shale fuel oil } & Dephenolated fuel oil \\
\hline A & $1.24548 \cdot 10^{3}$ & $1.18055 \cdot 10^{3}$ \\
B & $-8.03226 \cdot 10^{-1}$ & $-7.09138 \cdot 10^{-1}$ \\
C & $-3.72502 \cdot 10^{-2}$ & $-5.23979 \cdot 10^{-2}$ \\
D & $-2.63639 \cdot 10^{-5}$ & $-5.10395 \cdot 10^{-5}$ \\
E & $3.04502 \cdot 10^{-4}$ & $3.72620 \cdot 10^{-4}$ \\
F & $9.19393 \cdot 10^{-5}$ & $-3.84895 \cdot 10^{-5}$ \\
\hline
\end{tabular}




\subsection{Expansion coefficients, compressibilities and speeds of sound}

Thermal expansion coefficients (Equation 3) and isothermal compressibilities (Equation 4) were calculated by taking the appropriate partial derivatives of Equation 6, and these partial derivatives are given as Equations 7 and 8.

$$
\begin{aligned}
& \left(\frac{\partial \rho}{\partial T}\right)_{P}=B+E \cdot P+2 F \cdot T \\
& \left(\frac{\partial \rho}{\partial P}\right)_{T}=C+2 D \cdot P+E \cdot T
\end{aligned}
$$

In these equations all the variables and coefficients have the same values as in Equation 6 . The calculated expansion coefficients and isothermal compressibilities were then used with Equation 5 to calculate the speed of sound at the experimental conditions. The constant pressure heat capacity required for the Equation 5 was obtained from Equation 9 (for the shale fuel oil) and Equation 10 (for the dephenolated shale fuel oil).

$$
\begin{aligned}
& C_{p}=0.002911 T+1.009 \\
& C_{p}=0.002833 T+0.9918
\end{aligned}
$$

These linear equations were fit to experimental data (14 data points) measured in this work in the temperature range between 288.2 and $423.2 \mathrm{~K}$. In these equations $T$ is temperature $(\mathrm{K})$ and $C_{p}$ is the constant pressure heat capacity $\left(\mathrm{J} \mathrm{g}^{-1} \mathrm{~K}^{-1}\right)$. The $\mathrm{R}^{2}$ coefficients for these linear fits are 0.996 and 0.997 for Equations 9 and 10, respectively. Although the heat capacity also depends somewhat on pressure, this was not taken into account here. The effect of the pressure dependence on the speed of sound calculation is minor, as shown in Section 2.5.

The calculated expansion coefficients, isothermal compressibilities and speeds of sound along with expanded uncertainties at the $95 \%$ level are presented in Table 2 and Table 3 for fuel oil and dephenolated fuel oil, respectively.

The dephenolated sample had higher expansion coefficients and compressibilities, but lower speeds of sound. The relative difference between the fuel oil and dephenolated samples can be seen from Figure 2, Figure 3 and Figure 4. In these figures the relative difference was calculated using the fuel oil sample as the reference. These differences are larger than the expanded uncertainty of the data for almost all of the points, and taken as a whole there is a consistent positive or negative trend. Therefore, the phenolic compounds have a significant impact on the thermodynamic properties of the oil, as expected. As shown, the difference between the two samples increased with temperature and decreased with pressure. 


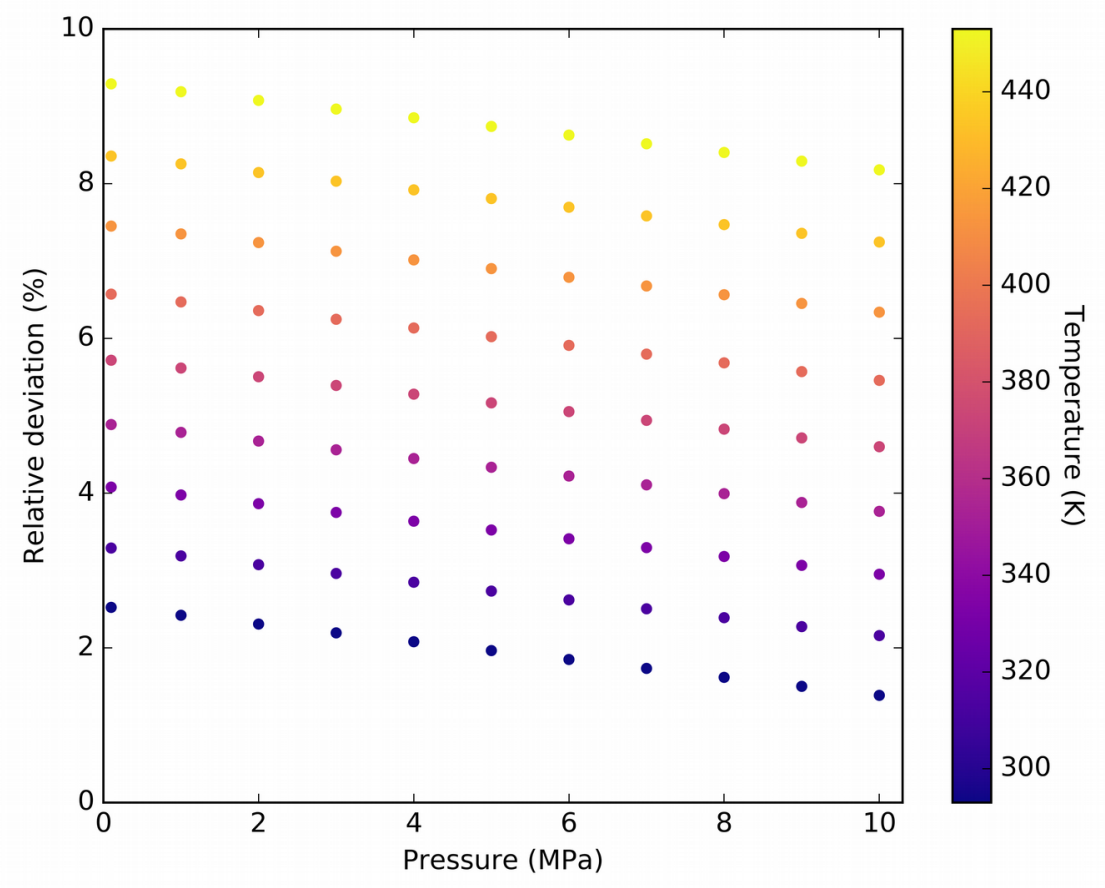

Figure 2. The relative deviation between the thermal expansion coefficients of the fuel oil and dephenolated samples. Relative deviation $=($ Dephenolated - Fuel oil $) /$ Fuel oil $* 100$.

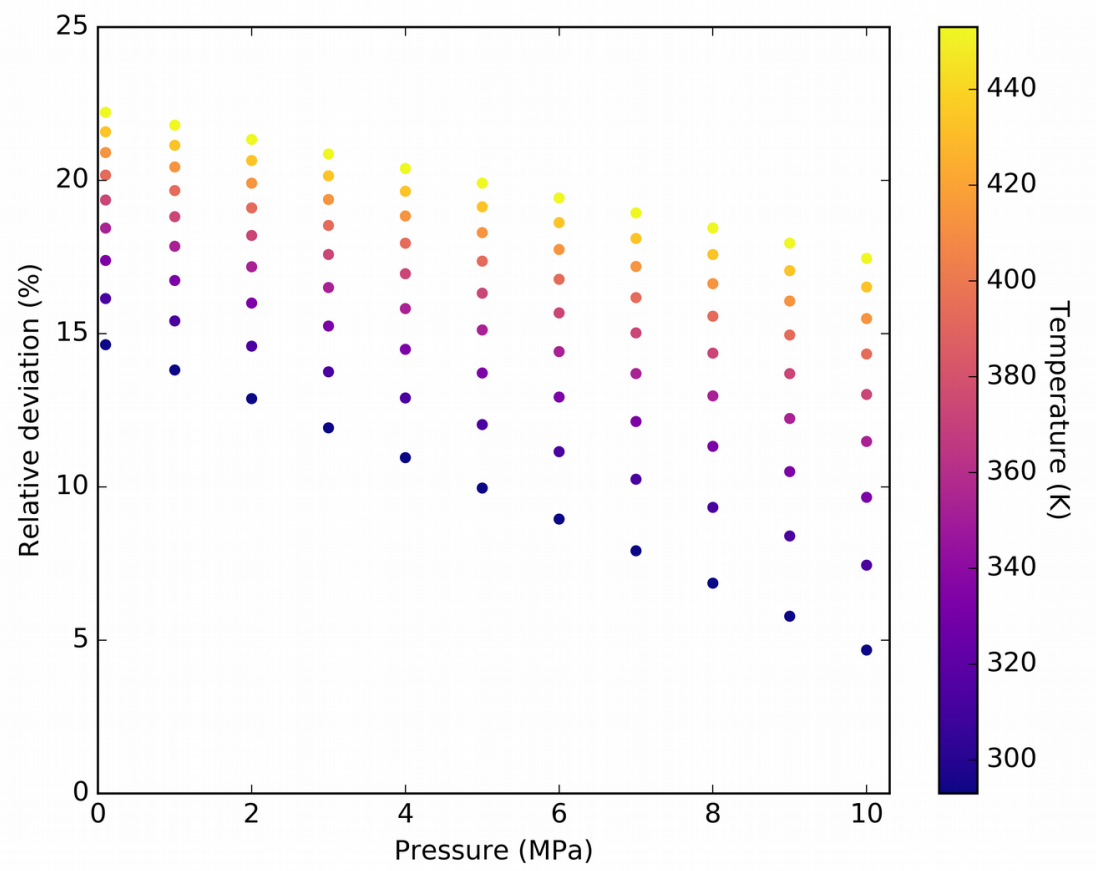

Figure 3. The relative deviation between the isothermal compressibilities of the fuel oil and dephenolated samples. Relative deviation $=($ Dephenolated - Fuel oil $) /$ Fuel oil $* 100$. 


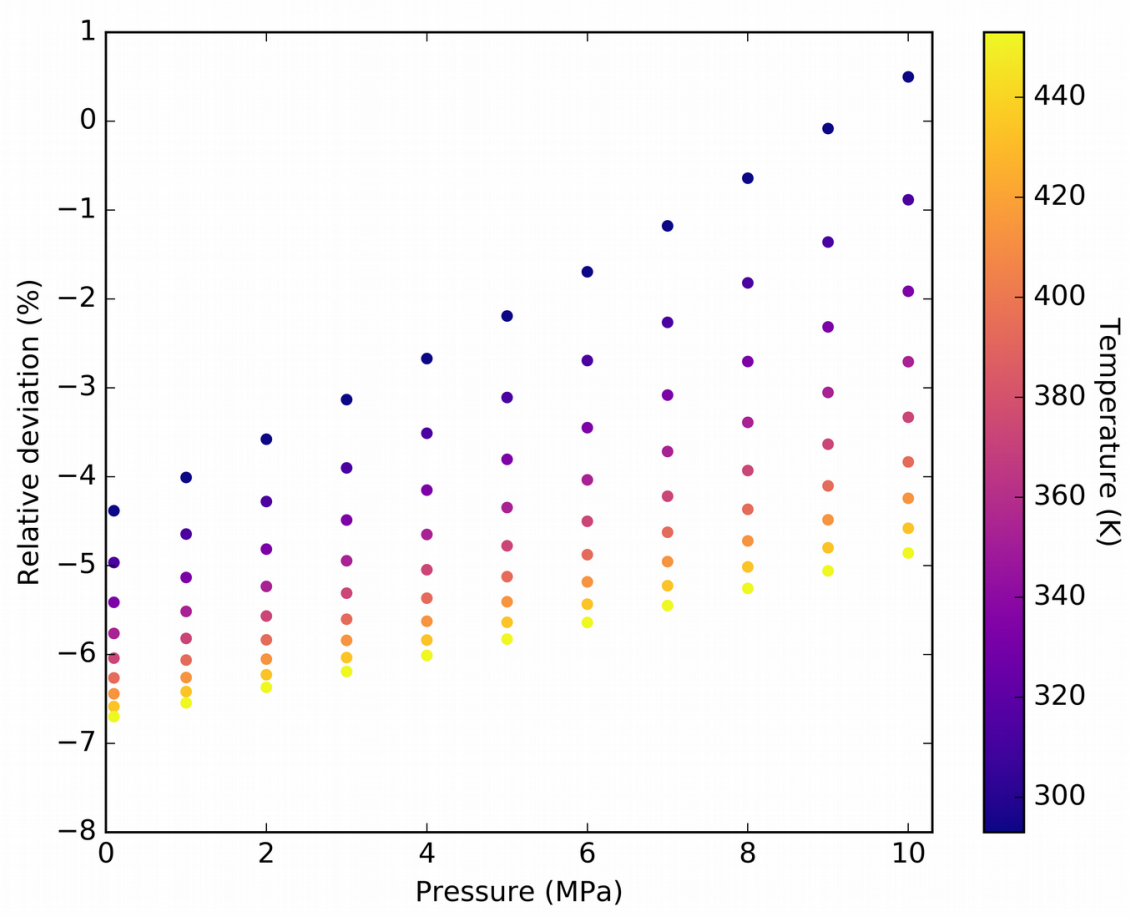

Figure 4. The relative deviation between the speeds of sound of the fuel oil and dephenolated samples. Relative deviation $=($ Dephenolated - Fuel oil $) /$ Fuel oil $* 100$.

For comparison we selected several different fuels and pure compounds. This comparison is given in Figure 5 and Figure 6, and shows that the shale oil samples have relatively low compressibilities. The petroleum fraction was a narrow distillation cut with an average boiling point of about $523 \mathrm{~K}^{45}$ The bio-derived jet fuels consisted mostly of linear and branched paraffins (BIO-SPK and Cs-HRJ samples in ${ }^{46}$ ). The curves shown in the figures were calculated by fitting polynomials to the experimental data given in the references and then using those polynomials to calculate the compressibility. This was done because the data for different compounds had been measured at different temperatures and pressures. Figure 5 presents a comparison in terms of pressure at $303 \mathrm{~K}$. The petroleum fraction and jet fuel samples had significantly higher compressibilities than the shale oil samples, as expected because these samples have lower boiling points and contain, on average, smaller molecules. However, even tridecylbenzene and pentadecylbenzene, which are larger compounds with molecular weights comparable to the shale oil samples, had compressibilities that were higher. Therefore, the polar and alkylaromatic character of Kukersite shale oil gives it compressibilities that are lower than fuels and pure hydrocarbons that have more of an aliphatic nature. Figure 6 shows a comparison in terms of temperature at a constant pressure of $2 \mathrm{MPa}$. In both figures the shale oil samples matched best with 1-methylnapthalene and quinoline, which are aromatic molecules with two rings. 


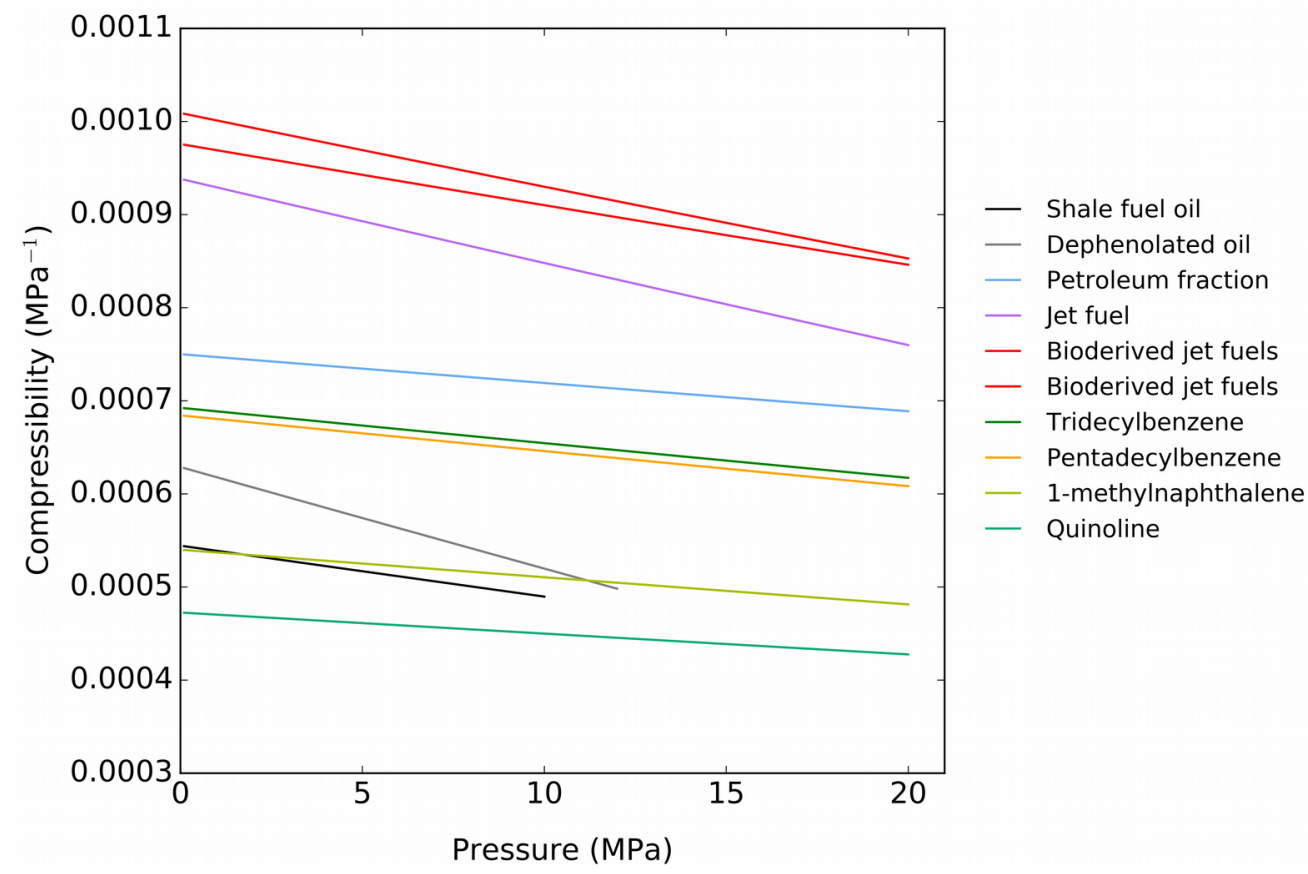

Figure 5. Comparison of the compressibilities at $303 \mathrm{~K}$ for the shale oil samples with literature data for a petroleum fraction, ${ }^{45}$ jet fuel, ${ }^{47}$ bioderived jet fuels, ${ }^{46}$ tridecylbenzene, ${ }^{48}$ pentadecylbenzene, ${ }^{48}$ 1-methylnaphthalene ${ }^{49}$ and quinoline ${ }^{49}$.

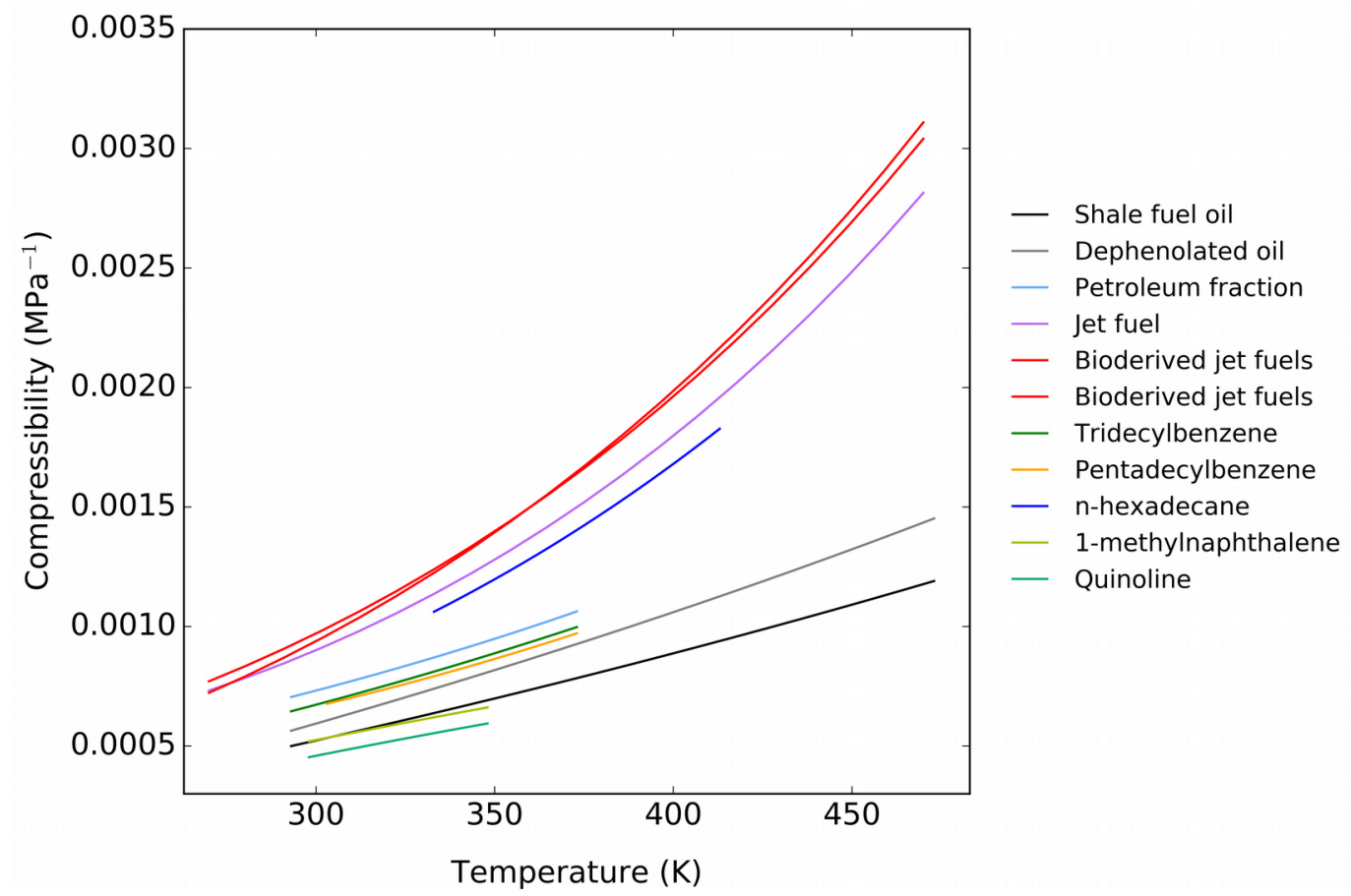

Figure 6. Comparison of the isothermal compressibilities at $2 \mathrm{MPa}$ for the shale oil samples with literature data for a petroleum fraction, ${ }^{45}$ jet fuel, ${ }^{47}$ bioderived jet fuels, ${ }^{46}$ tridecylbenzene, ${ }^{48}$ pentadecylbenzene, ${ }^{48}$ n-hexadecane,${ }^{50} 1$-methylnaphthalene ${ }^{49}$ and quinoline ${ }^{49}$. 
The speeds of sound determined for these shale oil samples are compared to literature values for common materials in Table 5 . Liquids in general have speeds of sound that are much higher than in air, but even among liquids the shale oil samples have high speeds of sound. Small molecules like tetrachloromethane and nonpolar alkanes like heptane and octane have much lower speeds of sound. Common fuels such as jet fuel and gasoline also have lower speeds of sound, likely because they often contain large amounts of alkanes and have lower molecular weights than the shale oil. The shale fuel oil sample has a speed of sound that is most similar to water and cresols. The similarity to cresol was expected because a main component of Kukersite shale oil is alkylphenols. The higher speed of sound is related to lower compressibilities.

Table 5. The speed of sound in various materials at ambient conditions (about $293 \mathrm{~K}$ and 1 bar).

\begin{tabular}{|c|c|c|}
\hline Material & $\begin{array}{c}\text { Speed of } \\
\text { sound }\left(\mathrm{m} \mathrm{s}^{-1}\right)\end{array}$ & Reference \\
\hline Air, dry & 343 & 51 \\
\hline Tetrachloromethane & 930 & 51 \\
\hline Hexane & 1078 & 51 \\
\hline Heptane & 1149 & 51 \\
\hline Octane & 1166 & 51 \\
\hline 1-propanol & 1223 & 51 \\
\hline 1-butanol & 1262 & 51 \\
\hline Jet fuel (from camelina) & 1262 & 46 \\
\hline 1-undecene & 1275 & 51 \\
\hline Kerosene & 1280 & 52 \\
\hline Oil (SAE 30) & 1280 & 52 \\
\hline Jet fuel (from castor seed oil) & 1284 & 46 \\
\hline Jet fuel (from waste fat and grease) & 1288 & 46 \\
\hline Jet fuel (from plant isoprenoid) & 1297 & 46 \\
\hline Cyclohexane & 1299 & 51 \\
\hline Benzene & 1302 & 51 \\
\hline Chlorobenzene & 1311 & 51 \\
\hline Jet fuel & 1317 & 47 \\
\hline Gasoline & 1380 & 52 \\
\hline Dephenolated shale fuel oil & 1450 & this work \\
\hline Mercury & 1450 & 52 \\
\hline Water (distilled) & 1483 & 52 \\
\hline m-Cresol & 1497 & 53,54 \\
\hline Eugenol & 1497 & 53 \\
\hline p-Cresol & 1503 & 53,54 \\
\hline Shale fuel oil & 1520 & this work \\
\hline o-Cresol & 1522 & 53,54 \\
\hline Water (sea, S = 3.5\%) & 1534 & 51 \\
\hline Glycerine & 1895 & 52 \\
\hline
\end{tabular}

\section{Conclusions}

The densities of two Kukersite shale oil samples were measured, and thermal expansion coefficients, isothermal compressibilities and speeds of sound were calculated from this data. The heat capacities of the samples were also measured, and empirical equations based on this data were presented. The experimental density data confirmed that removing polar phenolic compounds from the oil causes a noticeable decrease in the 
density, as would be expected. Removing phenolic compounds from the oil also caused changes in other thermodynamic properties of the shale fuel oil: the expansion coefficient and compressibility increased, the speed of sound decreased.

\section{Acknowledgements}

Part of the funding for this research came from a grant awarded by the European Regional Development Fund under the Dora Plus Program. The authors also thank Emilie Pedegert for her help with some of the measurements and Sven Kamenev for building the liquidliquid extraction device.

\section{References}

(1) Gross, J.; Sadowski, G. Perturbed-Chain SAFT: An Equation of State Based on a Perturbation Theory for Chain Molecules. Ind. Eng. Chem. Res. 2001, 40 (4), 12441260 DOI: $10.1021 / \mathrm{ie} 0003887$.

(2) Riazi, M. R. Characterization and Properties of Petroleum Fractions; ASTM International, 2005.

(3) Oja, V.; Rooleht, R.; Baird, Z. S. Physical and Thermodynamic Properties of Kukersite Pyrolysis Shale Oil: Literature Review. Oil Shale 2016, 33 (2), 184-197 DOI: 10.3176/oil.2016.2.06.

(4) Cady, W. E.; Seelig, H. S. Composition of Shale Oil. Ind. Eng. Chem. 1952, 44 (11), 2636-2641 DOI: 10.1021/ie50515a044.

(5) Baird, Z. S.; Oja, V.; Järvik, O. Distribution of Hydroxyl Groups in Kukersite Shale Oil: Quantitative Determination Using Fourier Transform Infrared (FT-IR) Spectroscopy. Appl. Spectrosc. 2015, 69 (5), 555-562 DOI: 10.1366/14-07705.

(6) Derenne, S.; Largeau, C.; Casadevall, E.; Sinninghe Damsté, J. S.; Tegelaar, E. W.; de Leeuw, J. W. Characterization of Estonian Kukersite by Spectroscopy and Pyrolysis: Evidence for Abundant Alkyl Phenolic Moieties in an Ordovician, Marine, Type II/I Kerogen. Org. Geochem. 1990, 16 (4), 873-888 DOI: 10.1016/01466380(90)90124-I.

(7) Dijkmans, T.; Djokic, M. R.; Van Geem, K. M.; Marin, G. B. Comprehensive Compositional Analysis of Sulfur and Nitrogen Containing Compounds in Shale Oil Using GC×GC - FID/SCD/NCD/TOF-MS. Fuel 2015, 140, 398-406 DOI: 10.1016/j.fuel.2014.09.055.

(8) Bartis, J. T.; LaTourrette, T.; Dixon, L.; Peterson, D. J.; Cecchine, G. Oil Shale Development in the United States: Prospects and Policy Issues; Rand Corporation, 2005.

(9) World Energy Council. World Energy Resources; World Energy Council: London, 2013.

(10) Oja, V.; Suuberg, E. M. Oil Shale Processing, Chemistry and Technology. In Encyclopedia of Sustainable Science and Technology; Mayer, R. A., Ed.; SpringerVerlag New York, 2012; pp 7457-7491.

(11) Oja, V. A Breaf Overview of Motor Fuels from Shale Oil of Kukersite. Oil Shale 2006, 23 (2), 160-163.

(12) Lee, S. Oil Shale Technology; CRC Press, 1990.

(13) Guo, S. H. The Chemistry of Shale Oil and Its Refining. In Coal, Oil Shale Natural Bitumen, Heavy Oil and Peat - Vol. II; Publishers Company Limited, 2009; Vol. 2, pp 94-106.

(14) Järvik, O.; Oja, V. Molecular Weight Distributions and Average Molecular Weights of Pyrolysis Oils from Oil Shales: Literature Data and Measurements by SEC and ASAP MS for Oils from Four Different Deposits. Energy Fuels 2016 DOI: 10.1021/acs.energyfuels.6b02452. 
(15) Urov, K.; Sumberg, A. Characteristics of Oil Shales and Shale-like Rocks of Known Deposits and Outcrops: Monograph; Oil shale Special; Estonian Acad. Publ: Tallinn, 1999.

(16) Kogerman, P. N. On the Chemistry of the Estonian Oil Shale "Kukersite."; Oil Shale Research Laboratory: Tartu, Estonia, 1931.

(17) Baird, Z. S.; Oja, V.; Järvik, O. Prediction of Pour Points of Kukersite Shale Oil: Influence of Phenols on Pour Point. In Abstract Book "ECC 10+ ECAB 3+ EPIC 5": 10th European Congress of Chemical Engineering; Nice, France, 2015; p 1466.

(18) Oja, V.; Järvik, O.; Baird, Z. S.; Rannaveski, R. Physical and Thermodynamic Properties of Phenol-Rich Oil from Oil Shale: Application of Correlations Based on Bulk Properties. In PetroPhase 2016; 2016.

(19) Albert, T.; Baird, Z. S.; Oja, V. Surface Tensions of Phenolic Moieties Rich Narrow Boiling Range Distillation Cuts from Kukersite Oil Shale Based Crude Oils. In Abstracts: 20th European Conference on Thermophysical Properties; Porto, Portugal, 2014.

(20) Golubev, N. Solid Oil Shale Heat Carrier Technology for Oil Shale Retorting. Oil Shale 2003, 20 (3), 324-332.

(21) Oja, V.; Elenurm, A.; Rohtla, I.; Tali, E.; Tearo, E.; Yanchilin, A. Comparison of Oil Shales from Different Deposits: Oil Shale Pyrolysis and Co-Pyrolysis with Ash. Oil Shale 2007, 24 (2), 101-108.

(22) Elenurm, A.; Oja, V.; Tali, E.; Tearo, E.; Yanchilin, A. Thermal Processing of Dictyonema Argillite and Kukersite Oil Shale: Transformation and Distribution of Sulfur Compounds in Pilot-Scale Galoter Process. Oil Shale 2008, 25 (3), 328 DOI: 10.3176/oil.2008.3.04.

(23) Baird, Z. S.; Uusi-Kyyny, P.; Oja, V.; Alopaeus, V. Hydrogen Solubility of Shale Oil Containing Polar Phenolic Compounds. Ind. Eng. Chem. Res. 2017, 56 (30), 87388747 DOI: 10.1021/acs.iecr.7b00966.

(24) Baird, Z. S. Predicting Fuel Properties From Infrared Spectra. PhD thesis, TUT Press: Tallinn, Estonia, 2017.

(25) Rannaveski, R.; Järvik, O.; Oja, V. A New Method for Determining Average Boiling Points of Oils Using a Thermogravimetric Analyzer. J. Therm. Anal. Calorim. 2016, 1-10 DOI: 10.1007/s10973-016-5612-6.

(26) A Reference Equation of State for the Thermodynamic Properties of Nitrogen for Temperatures from 63.151 to $1000 \mathrm{~K}$ and Pressures to $2200 \mathrm{MPa}$. J. Phys. Chem. Ref. Data 2000, 29 (6), 1361-1433 DOI: 10.1063/1.1349047.

(27) The IAPWS Formulation 1995 for the Thermodynamic Properties of Ordinary Water Substance for General and Scientific Use. J. Phys. Chem. Ref. Data 2002, 31 (2), 387-535 DOI: 10.1063/1.1461829.

(28) Bell, I. H.; Wronski, J.; Quoilin, S.; Lemort, V. Pure and Pseudo-Pure Fluid Thermophysical Property Evaluation and the Open-Source Thermophysical Property Library CoolProp. Ind. Eng. Chem. Res. 2014, 53 (6), 2498-2508 DOI: 10.1021/ie4033999.

(29) Thermophysical Properties of Fluid Systems http://webbook.nist.gov/chemistry/fluid/ (accessed Mar 14, 2017).

(30) Stabinger, H. Density Measurement Using Modern Oscillating Transducers; South Yorkshire Trading Company: Sheffield, 1994.

(31) Sabbah, R.; Xu-wu, A.; Chickos, J. S.; Leitão, M. L. P.; Roux, M. V.; Torres, L. A. Reference Materials for Calorimetry and Differential Thermal Analysis. Thermochim. Acta 1999, 331 (2), 93-204 DOI: 10.1016/S0040-6031(99)00009-X.

(32) Baird, Z. S.; Oja, V. Predicting Fuel Properties Using Chemometrics: A Review and an Extension to Temperature Dependent Physical Properties by Using Infrared Spectroscopy to Predict Density. Chemom. Intell. Lab. Syst. 2016, 158, 41-47. 
(33) Barron, R. F.; Barron, B. R. Design for Thermal Stresses; John Wiley \& Sons, 2011.

(34) Moran, M. J.; Shapiro, H. N.; Boettner, D. D.; Bailey, M. B. Fundamentals of Engineering Thermodynamics; John Wiley \& Sons, 2010.

(35) Crocker, M. J. Handbook of Acoustics; John Wiley \& Sons, 1998.

(36) Blakemore, J. S. Solid State Physics; Cambridge University Press, 1985.

(37) Zucker, R. D.; Biblarz, O. Fundamentals of Gas Dynamics; John Wiley \& Sons, 2002.

(38) Peiris, S. M.; Piermarini, G. J. Static Compression of Energetic Materials; Springer Science \& Business Media, 2009.

(39) Girifalco, L. A. Statistical Mechanics of Solids; Oxford University Press, USA, 2003.

(40) Boehman, A. L.; Morris, D.; Szybist, J.; Esen, E. The Impact of the Bulk Modulus of Diesel Fuels on Fuel Injection Timing. Energy Fuels 2004, 18 (6), 1877-1882 DOI: 10.1021/ef049880j.

(41) Evaluation of Measurement Data - Supplement 1 to the "Guide to the Expression of Uncertainty in Measurement" - Propagation of Distributions Using a Monte Carlo Method; Joint Committee for Guides in Metrology, 2008.

(42) Metiu, H. Physical Chemistry: Thermodynamics; Garland Science, 2006.

(43) Storn, R.; Price, K. Differential Evolution - A Simple and Efficient Heuristic for Global Optimization over Continuous Spaces. J. Glob. Optim. 11 (4), 341-359 DOI: 10.1023/A:1008202821328.

(44) Jones, E.; Oliphant, E.; Peterson, P. SciPy: Open Source Scientific Tools for Python. 2001.

(45) Lagourette, B.; Daridon, J. L. Speed of Sound, Density, and Compressibility of Petroleum Fractions from Ultrasonic Measurements under Pressure. J. Chem. Thermodyn. 1999, 31 (8), 987-1000 DOI: 10.1006/jcht.1999.0501.

(46) Outcalt, S. L.; Fortin, T. J. Density and Speed of Sound Measurements of Four Bioderived Aviation Fuels. J. Chem. Eng. Data 2012, 57 (10), 2869-2877 DOI: 10.1021/je3008149.

(47) Outcalt, S.; Laesecke, A.; Freund, M. B. Density and Speed of Sound Measurements of Jet A and S-8 Aviation Turbine Fuels. Energy Fuels 2009, 23 (3), 1626-1633 DOI: 10.1021/ef800888q.

(48) Dutour, S.; Carrier, H.; Daridon, J.-L.; Lagourette, B.; Gao, G.-H. Speed of Sound, Density, and Compressibility of Alkylbenzenes as a Function of Pressure and Temperature: Tridecylbenzene and Pentadecylbenzene. J. Chem. Eng. Data 2002, 47 (6), 1532-1536 DOI: 10.1021/je025560n.

(49) Chang, J. S.; Lee, M.-J. Densities of M-Cresol + Quinoline and m-Cresol + 1Methylnaphthalene Mixtures at (298 to 348$) \mathrm{K}$ and up to $30 \mathrm{MPa}$. J. Chem. Eng. Data 1996, 41 (2), 275-278 DOI: 10.1021/je950253I.

(50) Chang, J.-S.; Lee, M.-J.; Lin, H. Densities of Binary Mixtures of Hexadecane with MXylene and Tetralin from $333 \mathrm{~K}$ to $413 \mathrm{~K}$ and Pressures up to $30 \mathrm{MPa}$. J. Chem. Eng. Data 1998, 43 (2), 233-237 DOI: 10.1021/je970223d.

(51) Haynes, W. M. CRC Handbook of Chemistry and Physics, 94th Edition; CRC Press, 2016.

(52) Manglik, R. Heat Transfer Fluid Flow Data Books; Genium Publishing Corporation: Amsterdam, NY, USA.

(53) Cunha, D. L.; Coutinho, J. A. P.; Daridon, J. L.; Reis, R. A.; Paredes, M. L. L. Experimental Densities and Speeds of Sound of Substituted Phenols and Their Modeling with the Prigogine-Flory-Patterson Model. J. Chem. Eng. Data 2013, 58 (11), 2925-2931 DOI: 10.1021/je4003256.

(54) Bhatia, S. C.; Rani, R.; Bhatia, R.; Anand, H. Volumetric and Ultrasonic Behaviour of Binary Mixtures of 1 -Nonanol with o-Cresol, $\mathrm{m}$-Cresol, $\mathrm{p}$-Cresol and Anisole at $\mathrm{T}=$ 
(293.15 and 313.15) K. J. Chem. Thermodyn. 2011, 43 (3), 479-486 DOI: 10.1016/j.jct.2010.10.025. 